\title{
JOURNAL.RU
}

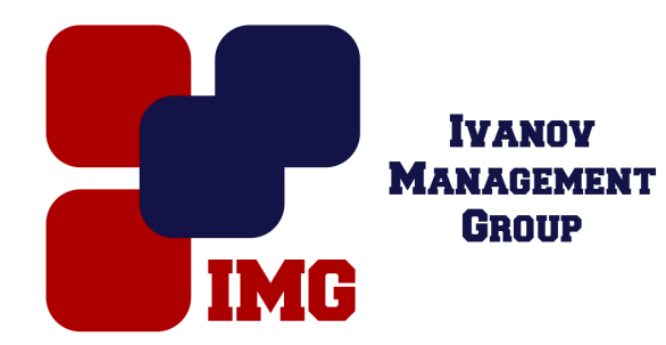

Ерошенко Я.Б., Самхарадзе К.К. ФГАОУ ВО НИУ «БелГУ» Белгород, Россия

doi: $10.18411 / 1 \mathrm{j}-31-07-2017-18$

idsp 000001:1j-31-07-2017-18

\section{Расширение области применения информационных технологий в бизнес-процессах}

\section{Аннотация}

Данная статья посвящена расчету оптимального объема партии поставки сырья. Проведен статистический анализ использования информационных технологий на предприятиях. Предложен способ расширения области применения информационных технологий в бизнес процессах путем использования разработанной программы «Управление запасами».

Ключевые слова: оптимальный объем запасов, управление запасами, максимально желательный запас, построение графика поставки запасов.

В современных условиях экономического кризиса, начавшегося введением в 2014 году санкций со стороны США и стран Западной Европы, многие российские промышленные предприятия наиболее сильно отреагировали на такие явления наступлением финансовой нестабильности и платежеспособности, сокращением темпов роста производительности труда.

В связи с этим многие хозяйствующие субъекты вынуждены использовать новые концепции основной стратегии развития, направленные на восстановление эффективности своей деятельности и разработке мер по стабилизации своего финансового состояния.

Одной из таких концепций выступают информационные технологии. В современном обществе - это неотъемлемый фактор влияния на эффективность 
экономики, продуктивность производства, актуальность управленческих решений.

К примеру, для сельхозпроизводителей в сложившихся экономических условиях для развития импортозамещения продукции агропромышленного комплекса (АПК) России необходимо сокращать длинную цепочку от самих производителей до конечного потребителя. Для этого они должны формировать новую информационную базу маркетинга, основанную на использовании специальных информационных ресурсов, типа «торговых онлайн площадок» (2).

В глобальных целях для обеспечения конкурентоспособности России, совершенствования системы государственного управления на основе использования информационных и телекоммуникационных технологий была утверждена государственная программа Российской Федерации «Информационное общество (2011 - 2020 годы)» (далее -Программа)(3).

Однако, по данным Росстата удельный вес организаций, использовавших специальные программные средства, в общем числе обследованных организаций за последнее время снизился, а затраты на их приобретение повысились (см. табл. 1) (4).

Таблица 1

Сравнительная характеристика по приобретению и использованию программных средств российскими организацияли

\begin{tabular}{|c|c|c|c|}
\hline Наименование & $\mathbf{2 0 1 4}$ г., \% & $\mathbf{2 0 1 5}$ г., \% & $\begin{array}{c}\text { Абс. откл. } \\
\text { (+, -) }\end{array}$ \\
\hline $\begin{array}{c}\text { Удельный вес организаций, использовавшие } \\
\text { специальные программные средства (всего) }\end{array}$ & 86,3 & 84,8 & $-1,5$ \\
\hline $\begin{array}{c}\text { Затраты на информационные и коммуникационные } \\
\text { технологии (приобретение программных средств) }\end{array}$ & 13,8 & 17,4 & 3,6 \\
\hline
\end{tabular}

В частности, снижение первого показателя происходило практически по всем видам информационных решений (см. рисунок 1).

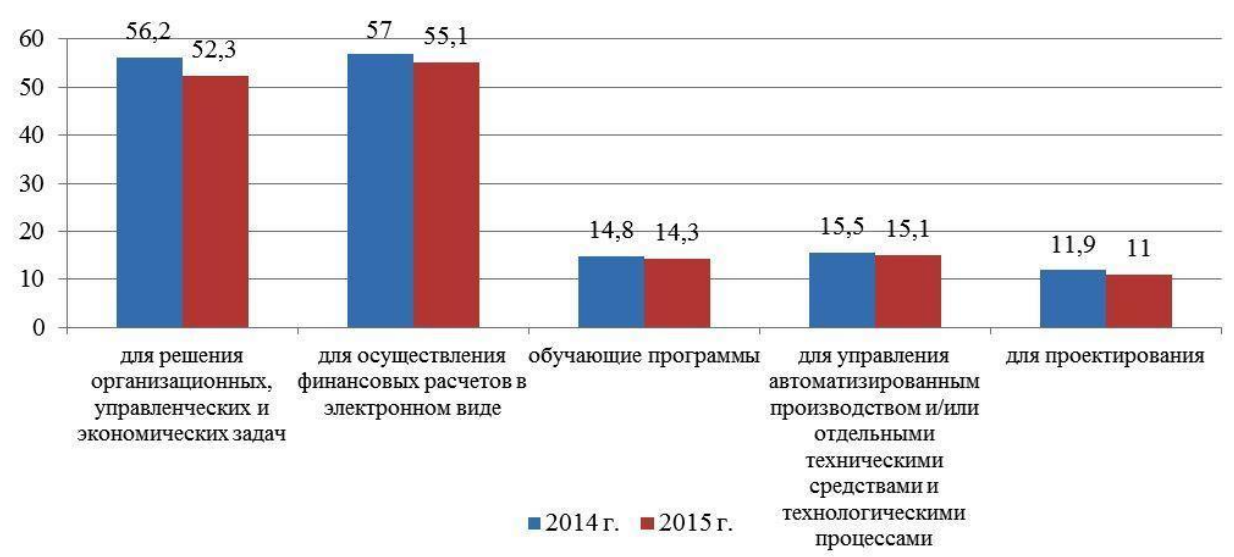

Рисунок 1. Удельный вес организаций, использовавиие специиальные программные средства, по видам информационньх задач 
Определяющее влияние на конкурентоспособность российских предприятий в условиях нестабильности рынка является обеспечение высокого уровня качества продукции, надежности ее поставки конечным потребителям. Этого можно достичь благодаря эффективному управлению запасами, основные направления которого должны сопровождаться совершенствованием технологии производства с использованием нестандартных инновационных решений.

Одним из таких решений является внедрение информационных технологий в управление бизнес-процессами путем использования специализированных программных средств.

В этой связи авторами статьи для контроля за состоянием запасов и облегчения процесса управления снабжением запасами и оборотными средствами, вложенными в эти запасы, разработана специальная программа «Управление запасами»с использованием скриптового языка программирования JavaScript, которая работает на веб-браузере посетителя.

С помощью данного программного продукта можно определить оптимальный объем партии поставки того или иного сырья, интервал поставки, размер страхового запаса сырья, максимально желательного запаса сырья (МЖ3), размер очередного заказа (Q) и построить график поставки сырья на предприятии.

Оптимальный объем партии поставки сырья характеризуется такой величиной размера партии поставки, при которой общие затраты минимальны и в учебной литературе именуется экономически обоснованным заказом (EOQ), математическая модель которого выражается формулой 1:

$$
\mathrm{EOQ}=\sqrt{2 \cdot \mathrm{V}_{\Pi \Pi} \cdot \frac{\mathrm{C}_{\mathrm{P} 3}}{\mathrm{C}_{\mathrm{XT}}}} .
$$

где VПП - годовой объем производственной потребности в данном сырье или материале;

СР3 - средняя стоимость размещения одного заказа;

СХT - стоимость хранения единицы товара в анализируемом периоде (5, с. 207).

Величину партии поставки (EOQ) можно взять за основу при определении интервала времени в модели управления запасами с фиксированной периодичностью заказов по формуле 2:

$$
\mathrm{t}=\frac{\mathrm{EOQ} \cdot \mathrm{T}}{\mathrm{V}_{\Pi \Pi}},
$$


Уже доказано, что при использовании данной модели на одном из ведущих предприятий г. Белгорода материальные затраты на приобретаемое сырье снизились, оборачиваемость материальных ресурсов увеличилась, что привело к экономии средств и, следовательно, к увеличению прибыли предприятия $(1$, с. 156).

Страховой запас $\left(3_{\text {стр }}\right)$ обеспечивает непрерывность производственного процесса при появлении некоторых негативных обстоятельств таких, как задержка в пути, изменение интенсивности потребления при увеличении спроса и др. Его размер в натуральных единицах определяется по формуле 2:

$$
3_{\text {стр }}=\Pi_{\text {сут }} \cdot \mathrm{H}_{\text {стр }} \text {, }
$$

где $\Pi_{\text {сут }}$ - среднесуточная потребность производственного запаса, шт.; $\mathrm{H}_{\text {стр }}$ - норма страхового запаса, дни $(6$, с. 35$)$.

МЖЗ определяется как сумма значений страхового запаса $\left(3_{\text {стр }}\right)$ и оптимальной партии заказа (EOQ) для исследуемого сырья.

Через фиксированные интервалы времени (t) требуется пополнение запаса до максимально желательного уровня и размер очередного заказа (Q) определяется по формуле 4:

$$
\mathrm{Q}=\mathrm{MЖ3}-3_{\text {тек }}(\mathrm{Z})+\Pi_{\mathrm{B} 3} \text {, }
$$

где Зтек(Z) - уровень текущего запаса при выдаче заказа, т; ПВ3 - ожидаемое потребление сырья за время выполнения заказа, т(7, с. 3).

Например, используя исходные данные предприятия с помощью программы «Управления запасами» произведем расчет графика поставки сырья.

Для этого запустим программу в окне браузера и введем необходимые значения, помеченные звездочкой «*» (см. рисунок 2).

\section{Управление запасами \\ ๑ 2017 Самхарадзе К.К.}

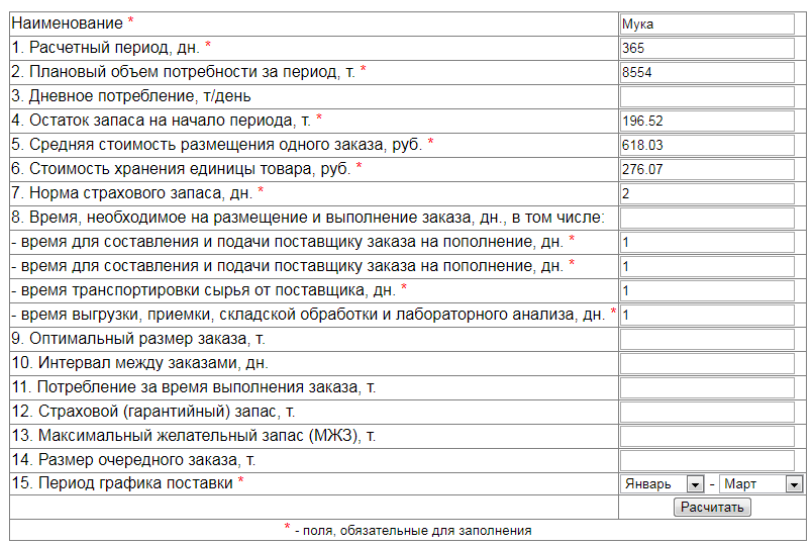

Рисунок 2. Ввод данных 
Далее при нажатии на кнопку «Рассчитать» ниже автоматически будет сформирован расчет партий поставки сырья (см. рисунок 3 ).

Расчет графика поставки для Мука

Период: Январь 2017 - Март 2017

\begin{tabular}{|c|c|c|c|c|}
\hline Дни & Остаток запаса, т & Расход в день & Поступление & Расчет заказа \\
\hline 1 & 2 & 3 & 4 & 5 \\
\hline 1 января 2017 & $196.52+0=196.52$ & 23.44 & 0 & Заказ $=242.58+196.52+93.76=139.82$ \\
\hline 2 января 2017 & 173.08 & 23.44 & - & \\
\hline 3 января 2017 & 149.64 & 23.44 & - & \\
\hline 4 января 2017 & 126.2 & 23.44 & - & \\
\hline 5 января 2017 & $102.76+139.82=242.58$ & 23.44 & 139.82 & \\
\hline 6 января 2017 & 219.14 & 23.44 & - & \\
\hline 7 января 2017 & 195.7 & 23.44 & - & \\
\hline 8 января 2017 & 172.26 & 23.44 & - & \\
\hline 9 января 2017 & 148.82 & 23.44 & - & Заказ $=242.58+148.82+93.76=187.52$ \\
\hline 10 января 2017 & 125.38 & 23.44 & - & \\
\hline 11 января 2017 & 101.94 & 23.44 & - & \\
\hline 12 января 2017 & 78.5 & 23.44 & - & \\
\hline 13 января 2017 & $55.06+187.52=242.58$ & 23.44 & 187.52 & \\
\hline 14 января 2017 & 219.14 & 23.44 & - & \\
\hline \multicolumn{5}{|c|}{$\cdots$} \\
\hline 25 марта 2017 & 78.5 & 23.44 & - & \\
\hline 26 марта 2017 & $55.06+187.52=242.58$ & 23.44 & 187.52 & \\
\hline 27 марта 2017 & 219.14 & 23.44 & - & \\
\hline 28 марта 2017 & 195.7 & 23.44 & - & \\
\hline 29 марта 2017 & 172.26 & 23.44 & - & \\
\hline 30 марта 2017 & 148.82 & 23.44 & - & Заказ $=242.58+148.82+93.76=187.52$ \\
\hline 31 марта 2017 & 125.38 & 23.44 & - & \\
\hline 1 апреля 2017 & 101.94 & 23.44 & - & \\
\hline 2 апреля 2017 & 78.5 & 23.44 & - & \\
\hline 3 апреля 2017 & $55.06+187.52=242.58$ & 23.44 & 187.52 & \\
\hline
\end{tabular}

Рисунок 3. Формирование расчета партий поставки сырья

На основании полученных данных расчета будет построен график поставки (см. рисунок 4).

\section{График поставки для Мука}

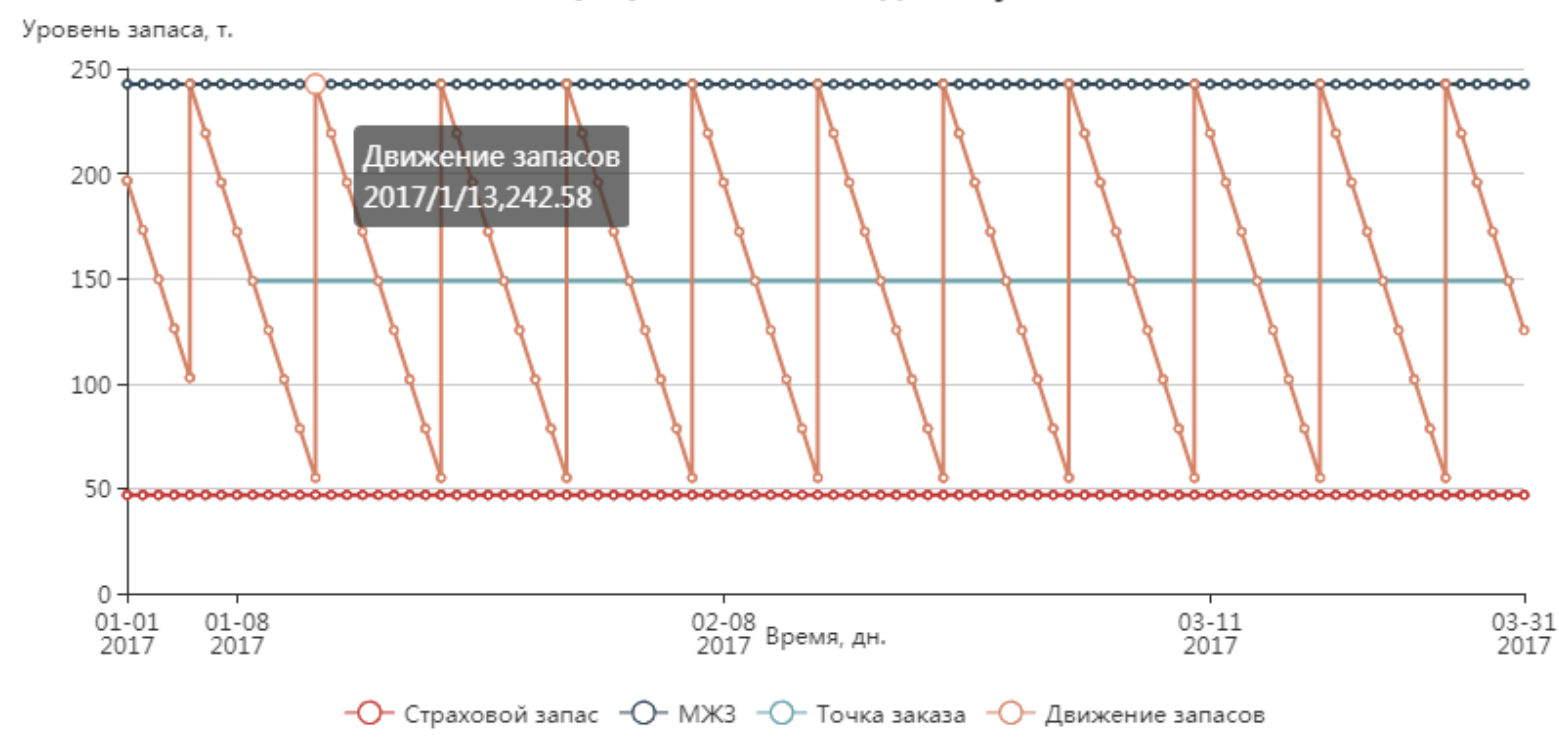

Рисунок 4. Формирование графика поставки сырья

Особенность разработанной программы заключается в построении таблицы расчета партии поставки и графика поставок. 
Для формирования таблицы расчета партии поставки необходимо определить общее количество дней, указанных в периоде графика поставки. Далее в цикле для каждого дня нужно определить, что происходит в этот день: формируется заказ партии сырья или происходит поступлении заказа (см. листинг 1).

Листинг 1 - Формирование расчета партии поставок:

varperiod_schedule $=0 * 1$;

for $(\operatorname{var} i=\$(" \# F R O M-"+I D) \cdot \operatorname{val}() ; i<=\$(" \# T O-"+I D) \cdot \operatorname{val}() ; i++)$

period_schedule+= new Date () .daysInMonth(i);

varinterval = 1 ;

DATA_ZCTR $=[] ;$ DATA_MGZ $=[] ;$ DATA_ORDER $=[] ; \quad$ DATA_OST $=[]$;

for (vari $=1$; $i<=$ period_schedule; $i++)\{$

date $=$ new Date (year, month, i);

schedule $+="\langle$ tr $\rangle "$; $\quad$ schedule $+="\langle\mathrm{td}\rangle "$ + ConvertDate $($ date $)+$ "</td $\rangle "$

if ( $i==$ interval) \{

DATA_OST.push(PushData(date, OST));

schedule $+="\langle\mathrm{td}\rangle "+$ OST $+"+"+\mathrm{Q}+"="+$ Round $($ OST $+\mathrm{Q}, 2)+"\langle/ \mathrm{td}\rangle "$;

$\mathrm{OST}=\operatorname{Round}(\mathrm{OST}+\mathrm{Q}, 2)$;

\}

else schedule $+="\langle\mathrm{td}\rangle "+$ OST $+"\langle/ \mathrm{td}\rangle "$;

schedule $+="\langle t d\rangle "+$ PSYT $+"</$ td $\rangle "$;

if ( $i==$ interval) schedule $+="\langle t d\rangle "+Q+"\langle/ t d\rangle "$;

else schedule $+="\langle t d\rangle-\langle/ t d\rangle "$;

if ( $i \% T Z==1)\{$

interval = $\mathrm{i}+\mathrm{TEXZ} ; \quad \mathrm{Q}=\mathrm{MGZ}-\mathrm{OST}+\mathrm{PVZ} ; \quad \mathrm{Q}=\operatorname{Round}(\mathrm{Q}, 2)$;

if (i != 1) DATA_ORDER.push(PushData(date, OST));

schedule += "<td $>$ Заказ = "+MGZ+ " + "+OST+" + "+PVZ+" = "+Q+" $</$ td $>"$;

\}

else schedule $+="\langle t d\rangle\langle/ t d\rangle "$;

DATA_OST.push(PushData(date, OST));

OST - = PSYT; OST = Round (OST, 2); $\quad$ schedule $+="</$ tr $>"$;

DATA_ZCTR.push(PushData(date, ZCTR)); DATA_MGZ.push(PushData(date, MGZ)); \} 
Построение графика осуществляется с помощью специальной jsбиблиотеки ECharts. Это огромная и обширная библиотека графиков и диаграмм созданная китайскими разработчиками. Она поддерживает огромное количество информации (см. листинг 2).

Листинг 2 - Формирование графика поставок:

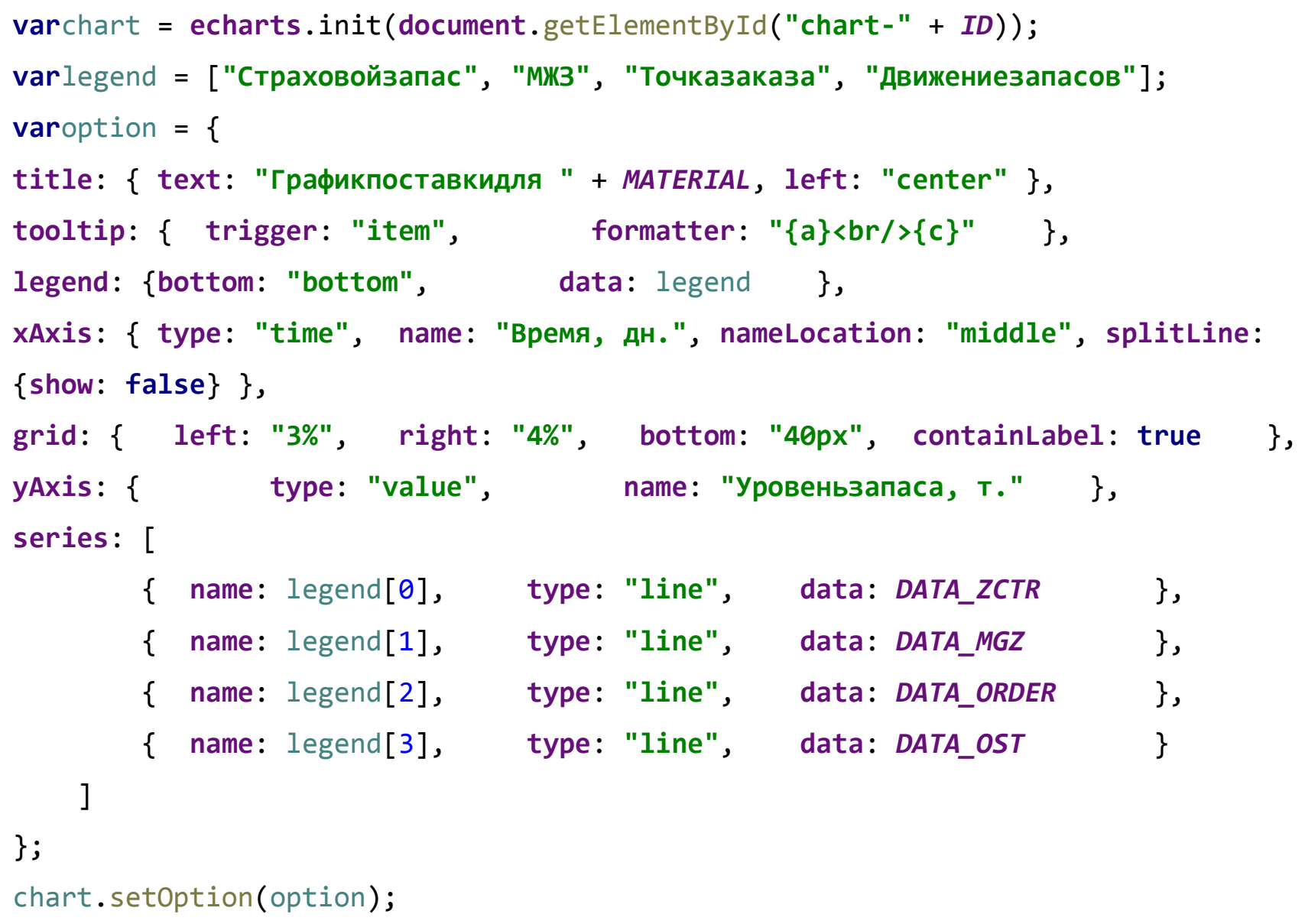

Использование данной программы будет актуальным для контроля над уровнем запаса сырья при изменении спроса на продукцию.

Например, по итогам 1 квартала на предприятии было установлено увеличение спроса на продукцию относительно 1 квартала прошлого периода. Для оптимизации затрат на сырье, используемого в производстве выпускаемой продукции, необходимо скорректировать объемы поставки данного сырья в строке 2 таблицы ввода (11856 т вместо 8554 т), остаток сырья на дату последнего поступления в строке 4 таблицы ввода (55.06)и выполнить расчет на следующий отчетный период (см. рисунок 5). 


\section{Управление запасами}

(c) 2017 Самхарадзе К.К.

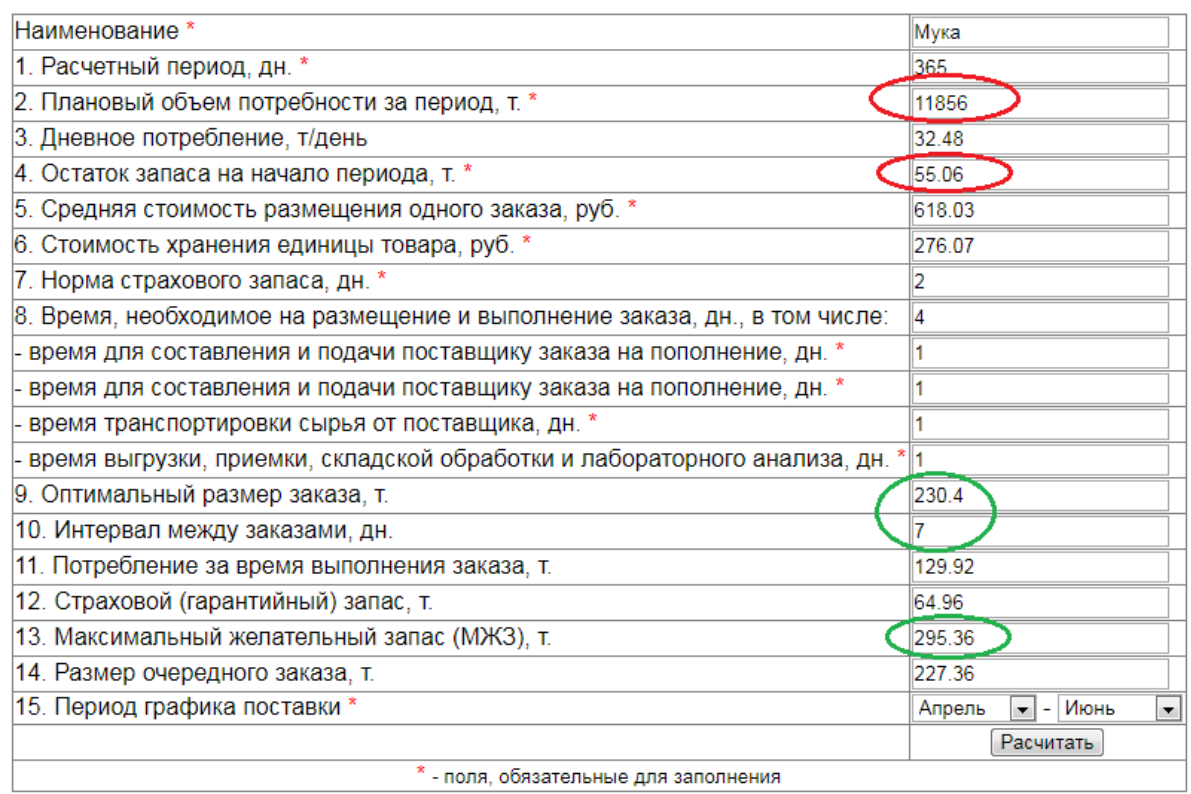

Рисунок 5. Ввод новых данных и формирование расчета

Произведенный заново расчет показывает увеличение оптимального объема партии поставки сырья в строке 9, интервала между заказами в строке 10 и объема МЖЗ сырья в строке 13 таблицы ввода.Полученные данные используются для своевременного изменения условий договора с поставщиком сырья, что повлияет на экономию средств и затрат предприятия на его приобретение.

Разработанная программа «Управление запасами» будет способствовать повышению эффективности организации системы управления запасами, экономичному использованию материальных ресурсов, что может оказать для предприятия решающее влияние на снижение издержек производства, себестоимости продукции, и, следовательно, повышение рентабельности производства и прибыльности работы всего предприятия. 
1. Герасимова Н. А. Способы оптимизации систем управления запасами на предприятиях в условиях экономического кризиса: научная статья / Н. А. Герасимова, А. К. Самхарадзе //Актуальные проблемы экономики в условиях реформирования современного общества: материалы IV междунар. науч.-практ. конф., посвященной 140-летию со дня основания НИУ «БелГУ». $-2016 .-460$ с.

2. Ерошенко Я.Б., Самхарадзе К.К.Расширение рыночного пространства для российских с/х производителей в условиях импортозамещения / Сборникнаучных трудов по материалам международной научно-практической конференции 12 июня 2017 г. [Электронный pecypc]: http://conf.sciencepublic.ru/wp-content/uploads/2016/07/spc12.06.2017.pdf (дата обращения 16.07.2017)

3. Минкомсвязь России / Целевые программы [Электронный ресурс]: Государственная программа «Информационное общество» (2011-2020 годы). - Режим доступа:https://rg.ru/2010/11/16/infobschestvo-site-dok.html (дата обращения 13.06.2017)

4. Официальный сайт Федеральной службы государственной статистики [Электронный pecyрc]: Информационное общество / Информационные и коммуникационные технологии. http://www.gks.ru/wps/wcm/connect/rosstat_main/rosstat/ru/statistics/science_and_innovations/i t_technology/\#(дата обращения 14.06.2017 г)

5. Савицкая Г. В. Анализ хозяйственной деятельности предприятия: учеб.пособие / Г. В. Савицкая. - М.: ИНФРА-М, 2009. - 536 с.

6. Стерлигова А. Н. Управление запасами в цепях поставок: учеб.пособие / А. Н. Стерлигова. - М.: ИНФРА-М, 2008. - 577 с.

7. Панферов Д. И. Управление запасами / Журнал «Планово-экономический отдел» №9 2012 г. [Электронный pecypc]: https://www.profiz.ru/peo/9_2012/oborotnij_kapital/(дата обращения 26.06.2017) 